\title{
Field evaluation of indigenous predacious insect, Chrysoperla carnea (Steph.) (Neuroptera: Chrysopidae), fitness in controlling aphids and whiteflies in two vegetable crops
}

\author{
A. Alghamdi', S. Al-Otaibi ${ }^{2}$ and S. M. Sayed ${ }^{2,3^{*}}$
}

\begin{abstract}
The green lacewing, Chrysoperla carnea (Steph.) (Neuroptera: Chrysopidae), is a generalist predator in its larval stage of most species of soft bodied insect pests, especially aphids, whiteflies, thrips, coccids, and mealy bugs. This predator had been recorded in different regions in Saudi Arabia as indigenous species. The fitness of this indigenous predator for controlling the aphid, Aphis gossypii Glov., and the whitefly, Bemisia tabaci (Genn.), with five and ten releasing rates on sweet pepper and squash plants in the open field was evaluated. The experiments were carried out in Taif region, Saudi Arabia, during the summer of 2017. On squash plants, the reduction was more than $90 \%$ after the third predator release of ten larvae per plant for both pests and reached 100\% only for the whitefly after six releases. On sweet pepper plants, reduction rates of the aphid and whitefly reached about 90 and $97 \%$, after the second predator release of five and ten larvae per plant, respectively. A 100\% reduction was achieved after four releases with five larvae/plant and three releases with ten larvae/plant. The present findings indicate that the releasing rates of five larvae/pepper plant and 10 larvae/squash plant were sufficient for suppressing both B. tabaci and $A$. gossypii populations.
\end{abstract}

Keywords: Green lacewing, Aphis gossypii, Bemisia tabaci, Squash, Sweet pepper, Fitness, Saudi Arabia

\section{Background}

The green lacewing, Chrysoperla carnea (Stephens) (Neuroptera: Chrysopidae), is a generalist predator. Adults feed only on nectar, pollen, and aphid honeydew, but its larvae are active predators. C. carnea occurs in a wide range of habitats (Henn and Weinzierl, 1990). It is considered as an effective generalist predator of most species of soft bodied insect pests, especially aphids, whiteflies, thrips, coccids, and mealy bugs (McEwen et al., 2001). C. carnea had been

\footnotetext{
* Correspondence: samy_mahmoud@hotmail.com

${ }^{2}$ Biotechnology Department, Faculty of Science, Taif University, Taif 888, Saudi Arabia

${ }^{3}$ Department of Economic Entomology and pesticides, Faculty of Agriculture, Cairo University, Giza 12613, Egypt

Full list of author information is available at the end of the article
}

recorded in different regions in Saudi Arabia as indigenous species, and it was molecularly identified by different mitochondrial genes (Sayed and Amer, 2015). Biological characteristics of the predator on the aphid species, Aphis fabae Scop., as a natural prey, and on Ephestia kuehniella (Zeller) eggs, as an alternative prey, were studied (Alghamdi and Sayed, 2017).

C. carnea has the adaptability to different environmental conditions and food diversity. It has a high searching capacity and a higher potential to prey on about 200 aphid species and more than 80 species of other insect pests (Tauber et al., 2000). C. carnea has been widely used for biological control of aphids and other 
insect pests because of its polyphagous habits and compatibility with selected chemical insecticides, microbial agents, and amenability for mass rearing (Uddin et al., 2005). It has been mass-reared and marketed commercially in the world, especially in North America and Europe (Tauber et al., 2000). Eggs of E. kuehniella are one of the most factitious preys for mass production of chrysopids' species because this food ensures quick growth and development, high survival rates, and higher fecundity (Specty et al., 2003).

Biological aphid control on sweet peppers (Capsicum annuum L.) includes applications of generalist predators and parasitoids (De Backer et al., 2015). The melon aphid, Aphis gossypii Glover (Homoptera: Aphididae), is one of the most common aphid species on sweet pepper plants (Sanchez et al., 2011). This pest species has a variation in its biological parameters and reproduction on different sweet pepper cultivars (Alizadeh et al., 2016).

Squash plants (Cucurbita pepo L.) are attacked by many insect pest species, especially A. gossypii (Nyoike and Liburd, 2010). Damage may be caused directly by sucking plants' juice or indirectly by transmitting plant viruses (Wu et al., 2010).

The whitefly, Bemisia tabaci (Gennadius) (Homoptera: Aleyrodidae), is one of the key pest species of sweet pepper and squash plants that causes direct damage by sucking the plant sap and indirect damage by transmitting of virus diseases (Banihashemi et al., 2017).

The present study aimed to evaluate the efficacy of releasing the indigenous $C$. carnea larvae for controlling A. gossypii and B. tabaci infesting sweet pepper and squash plants in open field trials.

\section{Materials and methods}

\section{Predator collection and mass rearing}

Individuals of $C$. carnea males and females were collected, using a 30-cm-diameter sweep net, from clover fields at Taif in west Saudi Arabia. The adults were maintained in a cylindrical plastic vessel $(10 \mathrm{~cm}$ diameter $\times 8 \mathrm{~cm}$ height $)$ with a hole $(4 \mathrm{~cm}$ in diameter) in the lid and covered with gauze for allowing proper ventilation inside the vessel. The adults were fed on an artificial diet as described by Sayed and Alghamdi (2017). Eggs laid in the vessels were carefully harvested, using forceps and breaking the stalk beneath the egg, and transferred to other vessels with the larval food. Eggs of E. kuehniella, sterilized with $\mathrm{UV}$, were used, as a factitious prey, for C. carnea larvae. The rearing was carried out under the controlled conditions of $25{ }^{\circ} \mathrm{C}, 60 \%$ R.H., and $16: 8$ photoperiods (L:D). The newly hatched larvae of the predator were used in continuing mass rearing for three generations, while the cocoons were collected daily and transferred to the vessels of adult rearing. The rearing of larvae was undertaken in the same plastic vessels described above and maintained with paper clips to reduce cannibalism. The rearing was continued during the whole experiment period in order to get the second instar larvae for releasing dates. The second instar larvae were selected and collected by a fine camel brush and transferred to releasing envelopes.

\section{Predator release in the field}

The experiment was carried out in Al Hada (Taif Governorate, Saudi Arabia) on two vegetable crops sweet pepper and squash during their vegetative and fruitage growth stages.

Randomized complete block design (RCBD) was practiced in an area of $(100 \times 200 \mathrm{~m})$ for each crop. Five blocks were used for each crop. Each block contained three plots (two treatments + control). Each plot was about $(2 \times 2 \mathrm{~m})$ and kept free from any pesticidal treatment. One plant was selected from each plot for the experiment. The distance between treatments and/or the control was about $50 \mathrm{~m}$. The C. carnea second instar larvae were released on the plants, at two rates (five and ten larvae per plant) as treatments. Thus, both treatments and the control were replicated five times (no. of plants sampled). The control was run without release of the predator.

Twenty envelopes (A5 size) containing the second larval instar of $C$. carnea were transferred to the field every releasing date (El-Arnaouty et al., 2000). Ten envelopes contained ten larvae and ten contained five larvae for each one. A paper sheet displaying E. kuehniella eggs was inserted in each envelope in order to avoid the cannibalism, until larval dispatching on the plants. Releasing of C. carnea second instar larvae started on July 28, 2017, and continued till September 16th (10-day intervals), with a total of six releases at the same rate on the same tested plant in both crops.

\section{Pests' count}

On the same day of the first predator release, aphid and whitefly nymphs/leaf were counted on each investigated plant and also on the same day of each subsequent release and in 10 days after the last release. Randomized three leaves from each treated and untreated plants were selected from different height of the plant and examined on both surfaces to count aphid and whitefly populations. These inspections were carried out using a $\times 4$ magnification lens in the field.

\section{Statistical analysis}

Duncan multiple range test, through one-way ANOVA (SPSS, 2015), was used to estimate the significance between the infestation rates of both pests. The 
reduction percentages in aphid and whitefly counts were calculated per plant leaf as a mean from each plant (five plants for each treatment) compared to the control. These percentages were estimated according to Abbott's (1925) formula because there were no significant differences among the treatments and the control for each pest density on both crops in the beginning of the experiment.

$$
\text { Reduction } \%=\frac{\text { Control count-Treatment count }}{\text { Control count }} \times 100
$$

The pest reductions (\%) were analyzed through six inspections, started 10 days after the first release. Reduction percentages of each pest were compared at the same inspection date for both pests, using $t$ test with a probability of $5 \%$ (SPSS, 2015).

\section{Results and discussion}

According to the General Authority of Meteorology and Environmental Protection (KSA), the minimum temperature during the experiment period ranged between 19 and $23{ }^{\circ} \mathrm{C}$, while the maximum temperature ranged between 33 and $35{ }^{\circ} \mathrm{C}$. The average humidity was $31 \%$ at daytime and $36 \%$ at night.

It was, generally, observed that the aphid and whitefly densities increased gradually from the end of July till the end of August on both investigated plants in the control (untreated), and then, the densities decreased gradually during September (Tables 1, 2, 3, and 4). This may be because the leaves of both plants became old with few vegetative growth.

Aphid densities did not differ significantly, 10 days after the first release, between the releasing rates of five second instar larvae (88.27 and 4.4 nymphs/ squash and pepper leaves, respectively) and the ten one (75.6 and 2.47 nymphs/squash and pepper leaves, respectively) (Tables 1 and 3). Meanwhile, whitefly densities, at this period, were significantly different between the releasing rates of five larvae (10.87 and 2.47 nymphs/squash and pepper leaves, respectively) and the ten one (6.2 and 0.6 nymphs/ squash and pepper leaves, respectively) (Tables 2 and 4). Moreover, the whitefly reduction on squash plants in this period was significantly different between both releasing rates (Table 1), while the reduction of aphid counts was insignificant (Table 2). This reduction reached more than $90 \%$ after the third release of ten larvae per plant for both pests and increased to $100 \%$ in the case of the whitefly only after six releases. The maximum reduction in the releasing rate of five larvae/plant was achieved after six releases $(74 \%$ for aphid and $64 \%$ for whitefly). Abrams and Matsuda (1996) indicated that sharing of two prey species to a predator may affect each other's densities positively because an increase in the populations of one pest species resulting in decreased predation on the other pest species. However, Messelink et al. (2008) stated that whitefly control of each of two predators in the absence of the thrips was not sufficient, while whitefly densities in the presence of thrips were reduced significantly.

On sweet pepper plants, the reduction in densities of both pests and after 10 days of the first release were significantly different (Tables 3 and 4). The aphid reduction reached about 90 and $97 \%$ after the second release of five and ten larvae per plant, respectively. A $100 \%$ reduction was achieved after four releases with five larvae/plant and three releases with ten larvae/plant (Table 3). The whitefly reductions seemed to be similar to those of aphids (Table 4). El-Arnaouty et al. (2000) obtained the best results from $M$. persicae control by releasing $C$. carnea second instar larvae on green pepper plants under greenhouse conditions, while the lower aphid suppression was achieved after releasing the combination of eggs and second instar larvae or eggs only of the predator.

The present findings indicate that the releasing rate of five larvae/pepper plant was sufficient for obtaining a good suppression of both B. tabaci and A. gossypii. Meanwhile, the releasing rate of ten larvae/squash plant was found adequate for better suppression of both pests. This result coincides with Zaki et al. (1999) who found that $C$. carnea induced highly significant reduction of $A$. gossypii and B. tabaci at different releasing rates on various vegetable crops.

Moreover, researchers such as Easterbrook et al. (2006) indicated that C. carnea is effective in open field than in protected crops and found that the aphid, Chaetosiphon fragaefolii infestation, was significantly reduced at the releasing rate of eight larvae/ strawberry plant in open field experiments but did not give a significant reduction in aphids under protected crops, even at a releasing rate of 25 larvae/ plant.

\section{Conclusions}

In conclusion, the obtained data showed that the aphid and whitefly populations on sweet pepper and squash plants, in open fields, were successfully suppressed by the releases of C. carnea. Control of two sap-sucking pests under investigation differed according to the releasing rate of the predator, at five and ten larvae per pepper and squash plant, respectively. The predatory action could be characterized as both curative and preventive. 


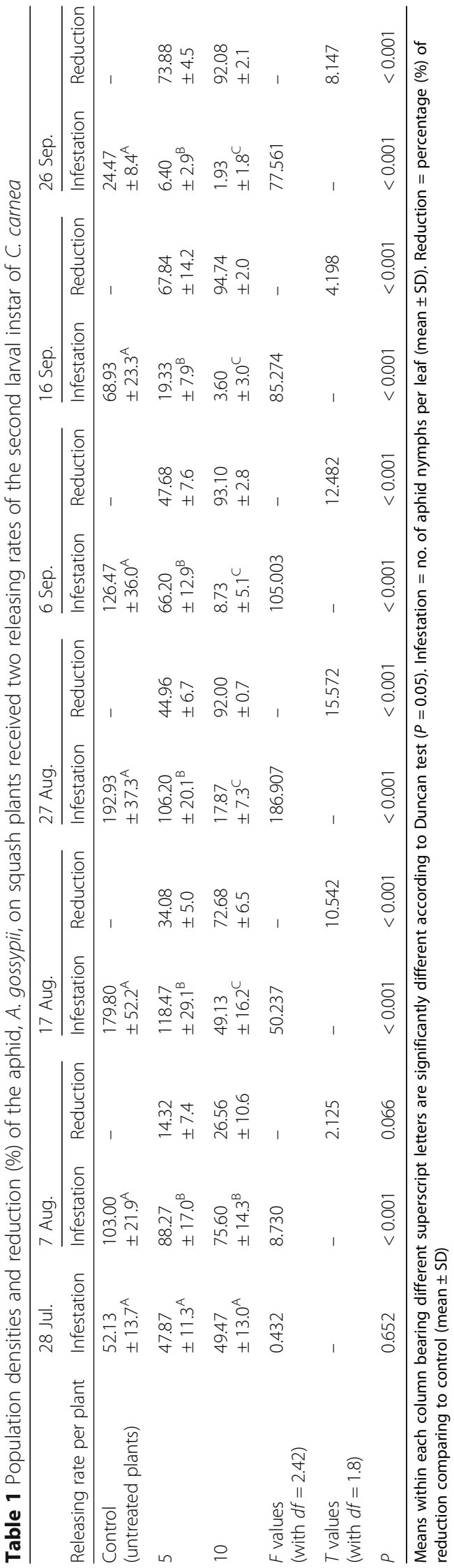




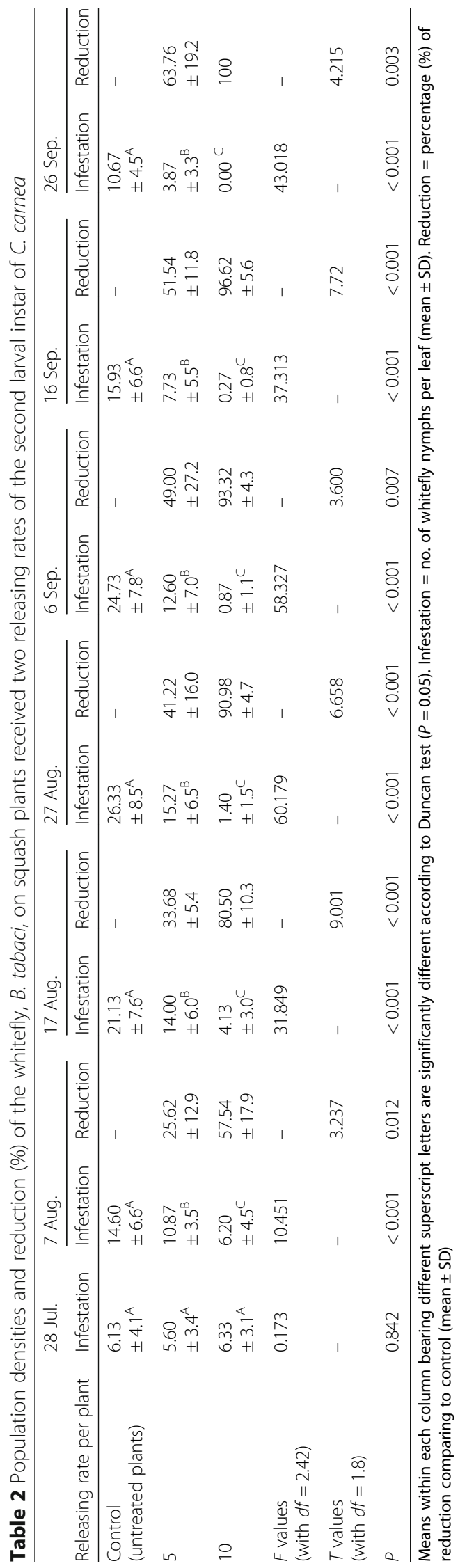




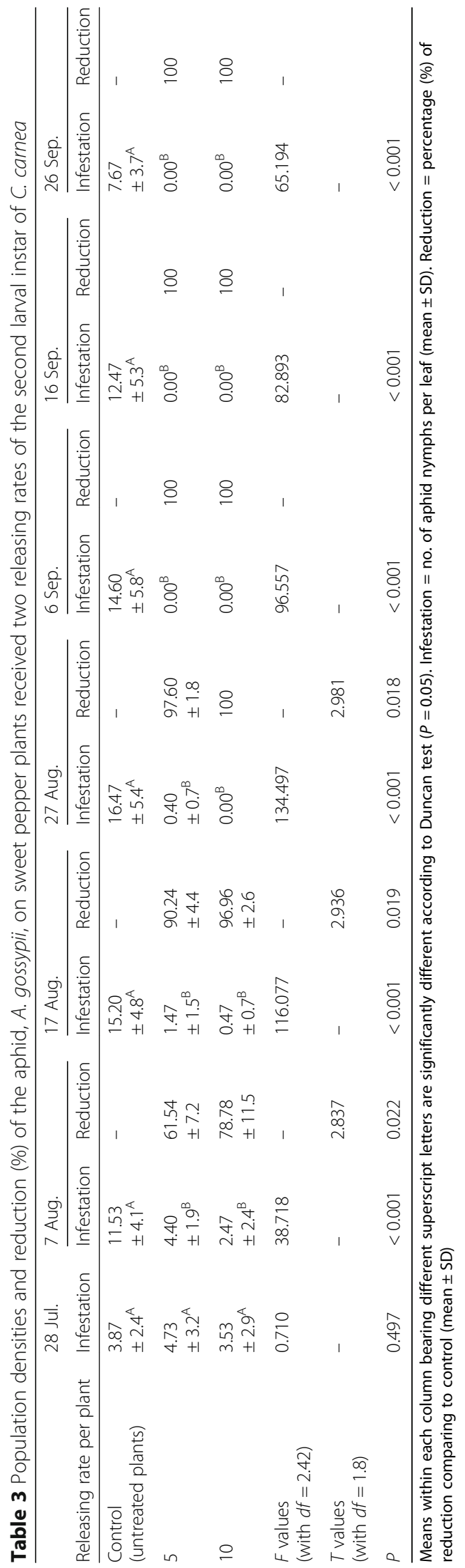




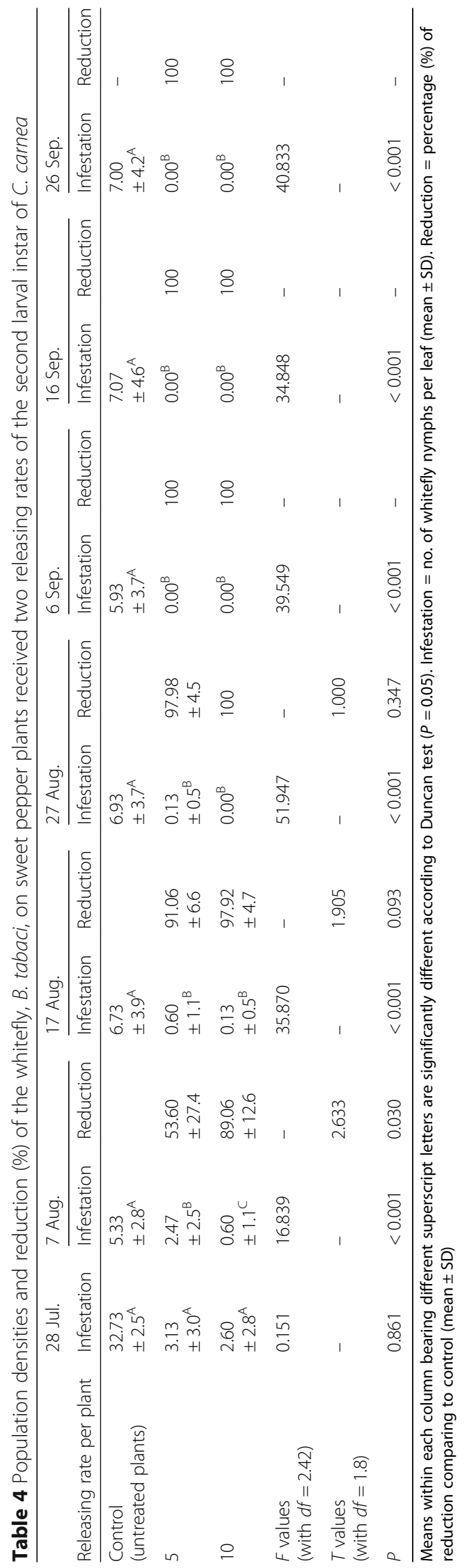




\section{Acknowledgements}

The authors would like to express their deepest gratitude to Taif University, Saudi Arabia, for the financial support for this study through a research grant number 5662-438-1.

\section{Authors' contributions}

All authors read and approved the final manuscript.

\section{Competing interests}

The authors declare that they have no competing interests.

\section{Publisher's Note}

Springer Nature remains neutral with regard to jurisdictional claims in published maps and institutional affiliations.

\section{Author details}

${ }^{1}$ Biology Department, Faculty of Science, Taif University, Taif 888, Saudi Arabia. ${ }^{2}$ Biotechnology Department, Faculty of Science, Taif University, Taif 888, Saudi Arabia. ${ }^{3}$ Department of Economic Entomology and pesticides, Faculty of Agriculture, Cairo University, Giza 12613, Egypt.

Received: 8 November 2017 Accepted: 3 January 2018

Published online: 01 March 2018

\section{References}

Abbott WS (1925) A method of computing the effectiveness of an insecticide. J Econ Entomol 18:265-267

Abrams PA, Matsuda H (1996) Positive indirect effects between prey species that share predators. Ecology 77:610-616

Alghamdi A, Sayed SM (2017) Biological characteristics of indigenous Chrysoperla carnea (Neuroptera: Chrysopidae) fed on a natural and an alternative prey. Asian J Biol 2(2):1-6

Alizadeh Z, Haghani M, Sedaratian A (2016) Biology and reproduction parameters of Aphis gossypii Glover, 1877 (Hemiptera, Aphididae) on five sweet pepper cultivars under laboratory conditions. Entomofauna 37(40):617-628

Banihashemi AS, Seraj AA, Yarahmadi F, Rajabpour A (2017) Effect of host plants on predation, prey preference and switching behaviour of Orius albidipennis on Bemisia tabaci and Tetranychus turkestani. Int J Trop Insect Sci 37(3):176-182

De Backer L, Wäckers FL, Francis F, Verheggen FJ (2015) Predation of the peach aphid Myzus persicae by the mirid predator Macrolophus pygmaeus on sweet peppers: effect of prey and predator density. Insects 6:514-523

Easterbrook MA, Fitzgerald JD, Solomon MG (2006) Suppression of aphids on strawberry by augmentative releases of larvae of the lacewing Chrysoperla carnea (Stephens). Biocontrol Sci Tech 16(9):893-900

El-Arnaouty SA, Gaber N, Tawfik MFS (2000) Biological control of the green peach aphid Myzus persicae by Chrysoperla carnea (Neuroptera: Chrysopidae). Egypt J Biol Pest Control 10(12):109-116

Henn T, Weinzierl R. (1990). Alternatives in insect pest management. Beneficial insects and mites. University of Illinois, Circular 1298. p 24. University of Illinois Cooperative Extension Service, USA: Urbana-Champaign, Illinois.

McEwen PK, New TRR, Whittington A. (2001). Lacewings in the crop environment UK: Cambridge University Press.

Messelink GJ, Maanen R, Steenpaal SEF, Janssen A (2008) Biological control of thrips and whiteflies by a shared predator: two pests are better than one. Biol Control 44:372-379

Nyoike TW, Liburd OE (2010) Effect of living (buckwheat) and UV reflective mulches with and without imidacloprid on whiteflies, aphids and marketable yields of zucchini squash. Int J Pest Manag 56(1):31-39

Sanchez JA, La-Spina M, Michelena JM, Lacasa A, de Mendoza AH (2011) Ecology of the aphid pests of protected pepper crops and their parasitoids. BioControl 21:171-188

Sayed SM, Alghamdi A (2017) Suitability of four different prey species for Dichochrysa tacta (Neuroptera: Chrysopidae). Biocontrol Sci Tech 27(2):200-209

Sayed SM, Amer SAM (2015) Molecular variability of Chrysoperla Steinman, 1964 (Neuroptera: Chrysopidae) inhabiting western Saudi Arabia. Pan Pac Entomol 91(2):101-107

Specty O, Febvay G, Grenier S, Delobel B, Piotte C, Pageaux JF, Ferran A, Guillaud J (2003) Nutritional plasticity of the predatory ladybeetle Harmonia axyridis (Coleoptera: Coccinellidae): comparison between natural and substitution prey. Arch Insect Biochem Physiol 52:81-91
SPSS. (2015) IBM SPSS Statistics for Windows (Version 23.0). Armonk, NY: IBM Corp. Chicago, IL.

Tauber MJ, Tauber CA, Daane KM, Hagen KS (2000) Commercialization of predators: recent lessons from green lacewings (Neuroptera: Chrysopidae: Chrysoperla). Am Entomol 46:26-38

Uddin J, Holliday NJ, Mackay PA (2005) Rearing lacewings, Chrysoperla carnea and Chrysopa oculata (Neuroptera: Chrysopidae), on prepupae of alfalfa leafcutting bee, Megachile rotundata (Hymenoptera: Megachilidae). Proc Entomol Soc Manitoba 61:11-19

Wu XH, Zhou XR, Ping PB (2010) Influence of five host plants of Aphis gossypii Glover on some population parameters of Hippodamia variegata (Goeze). J Pest Sci 83(2):77-83

Zaki FN, Shaarawy MF, Farag NA (1999) Release of two predators and two parasitoids to control aphids and whiteflies. J Pest Sci 72(1):19-20

\section{Submit your manuscript to a SpringerOpen ${ }^{\circ}$ journal and benefit from:}

- Convenient online submission

- Rigorous peer review

- Open access: articles freely available online

- High visibility within the field

Retaining the copyright to your article

Submit your next manuscript at springeropen.com 